
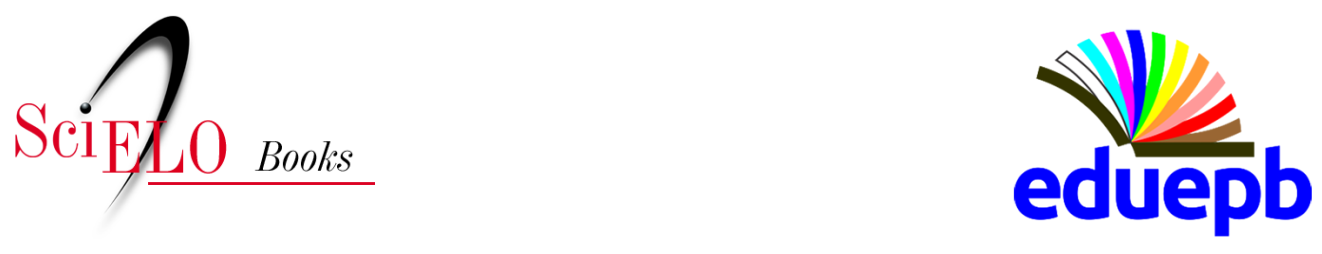

\title{
Utopias furtadianas \\ Luiz Gonzaga Belluzzo - Celso Furtado, um economista que apela para imaginação!
}

Ivo Marcos Theis

\section{SciELO Books / SciELO Livros / SciELO Libros}

THEIS, I. M. Luiz Gonzaga Belluzzo - Celso Furtado, um economista que apela para imaginação! Interviewed: Luiz Gonzaga Belluzzo. In: SOUSA, C. M., THEIS, I. M., and BARBOSA, J. L. A., eds. Celso Furtado: a esperança militante (Depoimentos): vol. 2 [online]. Campina Grande: EDUEPB, 2020, pp. 325-338. Projeto editorial 100 anos de Celso Furtado collection. ISBN: 978-65-86221-11-4. https://doi.org/10.7476/9786586221671.0017.

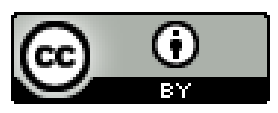

All the contents of this work, except where otherwise noted, is licensed under a Creative Commons Attribution 4.0 International license.

Todo o conteúdo deste trabalho, exceto quando houver ressalva, é publicado sob a licença Creative Commons Atribição 4.0.

Todo el contenido de esta obra, excepto donde se indique lo contrario, está bajo licencia de la licencia Creative Commons Reconocimento 4.0. 


\section{Luiz Gonzaga Belluzzo}
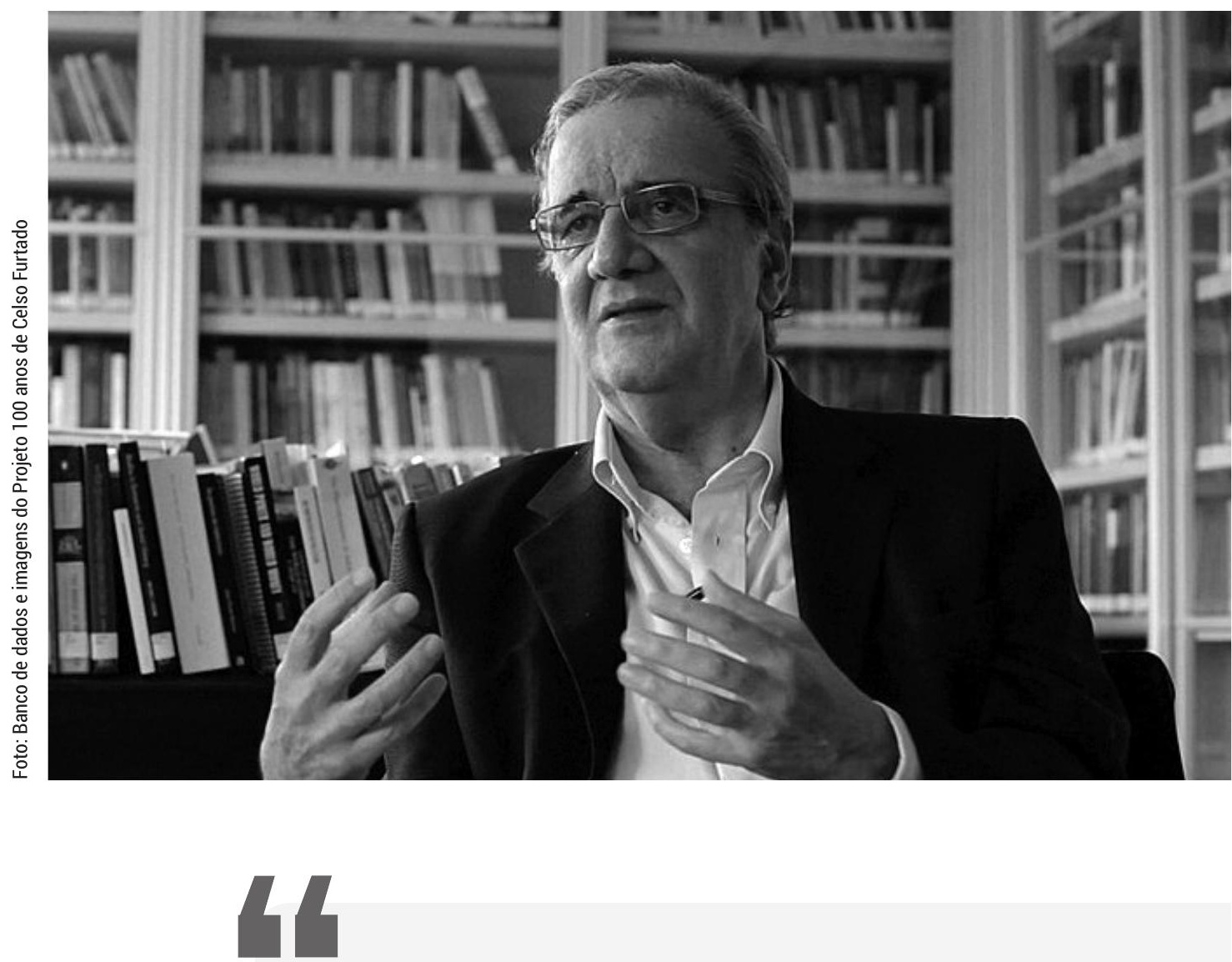

Celso Furtado tinha muito claro que precisava usar a imaginação. Certa vez ele se confessou positivista. Eu escrevi, aqui, uma orelha do livro dele, em que ele diz: "Eu sou positivista, não a caricatura que circula hoje em dia, mas a ideia de que o Homem tem meios para transformar 0 mundo. Construir um mundo melhor, que esses meios estão ordenados pela Ciência, decorrem do avanço formidável do conhecimento científico. 


\section{Celso Furtado, um economista que apela para imaginação!'}

uiz Gonzaga de Mello Belluzzo nasceu em Bariri, município do inteLrior do Estado de São Paulo, a 29 de outubro de 1942. Antes de ingressar no ensino superior foi seminarista da Companhia de Jesus. Com estes antecedentes, e por desejo do pai, acabaria se graduando, no ano de 1965, em Direito, na Universidade de São Paulo. O estudo das leis, contudo, foi devidamente temperado pelo contato com as ciências sociais da famosa Faculdade de Filosofia Letras e Ciências Humanas, da mesma USP. A aproximação que aí tivera com a economia seria intensificada em um curso de Desenvolvimento Econômico, promovido pela CEPAL, que Belluzzo concluiria em 1969. Sua formação se completaria com o doutoramento na Unicamp, em 1975 - o resultado seria "Valor e capitalismo: um ensaio sobre a economia política" (São Paulo: Brasiliense, 1980). Profissionalmente, foi docente colaborador na mesma Unicamp, aí se tornando professor titular, junto ao recém emancipado Instituto de Economia [IE], no ano de 1986.

A despeito de sua proximidade de (e sua inocultável simpatia por) Keynes - em 2016 publicou "O tempo de Keynes nos tempos do capitalismo” (São Paulo: Contracorrente) -, com os seus colegas do IE (entre os quais pontificavam João Manuel Cardoso de Mello, Luciano Coutinho, Maria da Conceição Tavares, Carlos Lessa, Antônio Barros de Castro, Carlos Alonso Barbosa de Oliveira, José Carlos de Souza Braga e Wilson Cano) dedicou-se, sob a forte influência de Celso Furtado, ao estudo da economia brasileira, a partir de uma base teórico-metodológica que incluía Karl Marx (e Friedrich Engels), o citado John Maynard Keynes, Joseph Alois Schumpeter, Michal Kalecki e Hyman P. Minsky.

Ao lado de suas atividades acadêmicas, não demorou a também intervir no debate público, para além dos muros da Unicamp, assessorando o PMDB entre meados dos anos 1970 e o início dos anos 1990. Neste tempo

1 Versão revista e adaptada, pelo autor, especialmente para este projeto, de aula/depoimento realizada no Instituto de Economia da Unicamp, em maio de 2019. O original está disponível em: https://www.youtube.com/watch?v=93gAH_wAs78 
foi Secretário de Estado em São Paulo, primeiro, de Ciência e Tecnologia, durante o governo Quércia, depois, de Economia e Planejamento, durante o governo Fleury. Também passou pelo Ministério da Fazenda, durante o governo Sarney, entre 1985 e 1987, quando o Brasil - afogado em uma inflação cavalar legada pela ditadura empresarial-militar - talvez tenha conhecido o seu melhor plano de estabilização, pelo menos, do ponto de vista de sua concepção.

Juntamente com outro economista, o amigo João Manuel Cardoso de Mello, foi um dos fundadores das Faculdades de Campinas (FACAMP). A partir de 2001, passou a ter seu nome registrado no influente "Biographical Dictionary of Dissenting Economists". Apenas quatro anos após, ganharia o Prêmio Juca Pato de "Intelectual do Ano". Por muitos anos, foi conselheiro da Fundação de Amparo à Pesquisa do Estado de São Paulo (FAPESP). E já por bastante tempo tem sido articulista dos mais lidos e também consultor editorial da mais séria revista semanal do país, "Carta Capital". Atento ao que se passava não apenas no Brasil, mas também para além dele, publicou em 2009 "Os antecedentes da tormenta: origens da crise global” (Campinas: Ed. Unesp; FACAMP) - referência para quem quisesse entender as turbulências que assolaram a economia mundial em 2007.

Belluzzo também gosta de futebol. E é notório torcedor do alviverde. Em 26 de janeiro de 2009, acabou eleito presidente do Palmeiras para um mandato de dois anos. Encontrando o clube endividado, mergulhado em problemas e um time pouco competitivo para disputar os campeonatos de 2009, o economista arregaçou mangas. Ainda naquele ano, após equilibrar contas e apagar incêndios, Belluzzo foi atrás de um novo estádio para o clube, que, mais tarde, viria a resultar na Arena Allianz Parque. Mas, em setembro de 2010, meses antes de encerrar seu mandato, acabou precisando afastar-se devido a um infarto. Continua ardoroso torcedor do Palmeiras, mas já não mais tão próximo das confusões do futebol.

Ao longo dos últimos anos, sem interromper sua produção intelectual - em 2019 publicou, com Gabriel Galípolo, "A escassez na abundância capitalista” (São Paulo: Contracorrente) -, também veio a presidir o Conselho Curador da "Empresa Brasil de Comunicação" (EBC), que opera a "TV Brasil", a fazer consultoria de economia para o ex-presidente Luiz Inácio Lula da Silva e a integrar o Conselho Deliberativo do "Centro Internacional Celso Furtado de Políticas para o Desenvolvimento".

Aliás, Belluzzo conhece a obra de Furtado como pouquíssimos. No depoimento que oferece a seguir ensina que "a grande virtude de Celso 
Furtado é essa concepção de desenvolvimento como um fenômeno que procura entender [...] a dinâmica das estruturas". Ele "vai mostrando como as configurações da economia mundial vão se transformando e vão mudando a posição dos países envolvidos. Celso [Furtado] partia da totalidade para observar as singularidades".

Evidentemente, Belluzzo não para por aí. Nas próximas linhas poder-se-á constatar não apenas uma justa compreensão das lições do "mestre" (como Maria da Conceição Tavares interpelava a Furtado), mas também sua grande simpatia pelo pensamento furtadiano e - talvez, involuntária, mas, sem dúvida, naturalmente - sua identificação com as causas abraçadas pelo grande economista paraibano.

(Ivo Marcos Theis)2

\section{Depoimento}

- A mim coube falar sobre Celso Furtado. E nós, eu e os mais velhos, tivemos a oportunidade de conviver com ele. Ele era um brasileiro que nos faz falta. Porque, antes de ser um intelectual, Celso Furtado era um homem público, um servidor público. Vocês sabem que ele foi responsável pela criação da Sudene, que foi Ministro do Planejamento do Governo João Goulart, que fez o Plano Trienal, que naquela ocasião contemplava as reformas que o Brasil precisava fazer, como a reforma urbana, a reforma financeira [...] Eu conversava muito com ele e ele tinha problema com Keynes. Muita gente tinha. Mas, generoso e inteligente como ele era, ele aceitava minhas observações [...] Mas, ele tinha uma sólida formação histórico-cultural. A grande virtude de Celso Furtado é essa concepção de desenvolvimento como um fenômeno que procura entender o que o professor João Manoel [Cardoso de Mello] chamou de dinâmica das estruturas. O que significa a dinâmica das estruturas?

2 Economista, $\mathrm{PhD}$ em Geografia Humana pela Eberhard-Karls Universität Tübingen (Alemanha), docente pesquisador do Programa de Pós-graduação em Desenvolvimento Regional da Universidade Regional de Blumenau (FURB), editor da Revista Brasileira de Desenvolvimento Regional. 
- Celso Furtado, a partir do [Raul] Prebisch, nosso fundador da CEPAL, que ele dizia ter uma visão estrutural sincrônica, se imaginou desenvolvendo essa ideia do Prebisch de centro-periferia de uma forma diacrônica. Ele dizia que o Prebisch olhava sincronicamente os vários momentos da relação centro-periferia. E que ele colocou isso numa perspectiva diacrônica.

\section{4}

Furtado dizia que Prebisch olhava sincronicamente os vários momentos da relação centro-periferia. $E$ que ele colocou isso numa perspectiva diacrônica. $\mathrm{Ou}$ seja, histórica. E ele fez isso magnificamente bem na Formação Econômica do Brasil.

Ou seja, histórica. E ele fez isso magnificamente bem na Formação Econômica do Brasil. Porque vai mostrando como as configurações da econômica mundial vão se transformando e vão mudando a posição dos países envolvidos. Celso partia da totalidade para observar as singularidades. Eu até brinquei uma vez com ele, conversando na casa de [Maria da] Conceição [Tavares], que ele era um tanto hegeliano, que olhava a totalidade para desvendar o fenômeno singular. Aliás, isso é uma capacidade, uma forma de ver que quase todos os economistas desconsideram ao se engalfinhar com modelos formais. Não estou falando contra o formalismo, até porque eu tenho uma boa formação matemática, de Bertrand Russell, Gödel etc. Foi essa a abordagem histórico-cultural que Celso Furtado desenvolveu a partir de Prebisch, em seu famoso estudo de 1949. O estudo de 1949 é uma ruptura, que nasce em Prebisch, por conta da crise atravessada por países periféricos depois do período de 1929, 1930 etc. Vocês sabem que Getúlio [Vargas] recebeu Prebisch. Sabiam? Junto com quem? Celso Furtado. E Roberto Campos. Você vê que os liberais daquele tempo eram mais ilustrados do que esses com os quais convivemos hoje. Roberto Campos esteve em Bretton Woods. Vocês sabiam disso? Não? Ele era funcionário da Embaixada Brasileira e estava fazendo o mestrado dele, cuja tese foi inspirada pela Teoria dos Ciclos de Gottfried [von] Haberler. É preciso entender que nesse momento há certo consenso partilhado por gente que não se considerava da mesma corrente, intelectuais, burocracia pública etc. Vou ler uma passagem de Fantasia Organizada. Vocês já leram? Não precisa dizer que leram se vocês não leram, não tem problema nenhum. Vocês vão ler. Fantasia Organizada - e eu abri aqui - é a história da construção 
do que mais tarde viria a se chamar "desenvolvimentismo". Eu acho o nome pobre para designar o que é.

- Mas, em Fantasia Organizada, Furtado escreve uma espécie de livro de memórias. Ele recupera a trajetória desta corrente que mais tarde iria se instaurar no Brasil, na busca do que ele chama de ruptura com o existente. Eu não vou dar uma aula acadêmica, porque eu não tenho mais paciência para isso. Mas, há uma conversa dele com o professor Eugênio Gudin, [...] um engenheiro ultraconservador que passou a se dedicar à Economia. [Gudin] escreveu [...] Elementos de Economia Monetária, um livro "wickselliano". Não tão ruim porque, em geral, os livros dos conservadores não sabiam explicar direito o que é o dinheiro. Aliás, isso está na origem da Economia Clássica. Mas, [Knut] Wicksell, um economista sueco, [...] pai da Escola Austríaca, coitado, não imaginou que tivesse essa descendência tão terrível. Mas, ele escreveu um livro chamado Interest and Prices, em que procurou explicar as relações do dinheiro com a Economia Real. E Gudin pegou a trilha de Wicksell - que dizia: "infelizmente vamos ter que considerar esse negócio do dinheiro". Vem lá dos pós-ricardianos a ideia de que a poupança financiava o investimento. Primeiro, você poupava, depois você investia. Mas, Wicksell dizia: "Há um problema aqui, há um negócio chamado banco, que tem a capacidade de financiar na frente". $\mathrm{O}$ banco, tendo essa capacidade de adiantar liquidez mediante operações de crédito, teria que se comportar, para não romper esse equilíbrio entre o consumo presente e o consumo futuro (investimento). Não preciso dizer a vocês que a ideia de equilíbrio, naturalidade e cálculo individual conformam toda a base da Economia Clássica e a Ortodoxia Contemporânea. Equilíbrio, cálculo individual, racional e a naturalidade do sistema econômico. O que quer dizer naturalidade? Isso corresponde às leis naturais. Isso vem desde Adam Smith, passa por [David] Ricardo, vem para os pós-ricardianos etc.

- Eugênio Gudin, a partir deste paradigma, sustentava que o Brasil não poderia ser um país industrializado. Eu posso dizer para vocês o que ele disse para Celso Furtado, numa reunião privada? Algo terrível. Talvez a gente encontre, hoje, gente ainda pior. Gudin dizia que o Brasil não poderia se industrializar porque era um país de mestiços, não poderia arcar com esse projeto que exigia gente qualificada, dotada de conhecimento, que sabia inovar etc. Um país de mestiços 
deveria mesmo produzir café. Vocês estão me olhando espantados, mas é verdade.

- Se vocês pegarem o debate de Gudin com Roberto Simonsen, o famoso Debate Simonsen-Gudin, e prestarem atenção ao que Gudin estava dizendo, se darão conta que ele estava dizendo isso, de outra maneira. Ele não podia dizer, porque o debate era público e ele não diria assim diretamente, mas ele pensava exatamente assim. Aliás, digamos que uma boa parte do establishment brasileiro não mudou de opinião. Eu fiz esse introito só para ler o que ele [Celso Furtado] diz de Gudin: "O Brasil não era apenas um país condenado a viver na agricultura, era também um país de solos pobres". A terra era pobre, e ele a comparava com a pampa argentina, que era naturalmente fértil. Ele achava que a industrialização era um fenômeno natural, e que o Brasil estava naturalmente indisposto com esse projeto.

- Celso diz o seguinte: "O professor Gudin me disse um dia, em tom de reprimenda: Você apela demasiadamente para a imaginação em suas análises. Devia ter sido romancista, não economista". Celso diz o seguinte, na Dialética do Desenvolvimento, eu não gosto, mas isso é um problema meu. Não vou ficar falando disso. Vou falar do que é crucial. Então, ele diz o seguinte. Vejam que sujeito interessante. Isso é 1949! No momento em que ele está divulgando um estudo do Prebisch! Ele diz o seguinte: "Ao invés de reduzir a realidade a um modelo, esforcei-me a adotar um enfoque histórico, abarcando o que cabia e o que não cabia no marco explicativo do economista". Ele não se considerava um economista. Ele se considerava um servidor público, um homem interessado nos problemas brasileiros. "A visão de Prebisch era essencialmente sincrônica...”, como eu disse para vocês, "assinalava uma descontinuidade estrutural no sistema capitalista, geradora de dinâmicas distintas nos segmentos central e periférico. Quando comparava o comportamento do sistema na época em que o centro principal era a Grã-Bretanha com o da época em que esse centro passou a ser os Estados Unidos, ele se limitava a fazer a interface dos dois cortes sincrônicos". 
- Essa observação é muito importante, porque Celso desenvolveu, na verdade, [...] a dinâmica histórica com mudanças nas posições dos elementos que faziam parte desse sistema global. O pessoal fala hoje de globalização. Mas, o fato é que no momento em que Celso escrevia, o fenômeno do subdesenvolvimento era estudado como decorrente do movimento das estruturas globais.

- Primeiro, a hegemonia inglesa, depois, a crise da hegemonia inglesa, nos anos 1920 e 1930, e o papel crescente dos Estados Unidos. Ele diz: "Interessava-me captar o desenrolar dos acontecimentos" - eu acho que todas essas palavras são importantes - "no tempo, o encadeamento dos fatores que perpetuavam o atraso clamoroso da economia brasileira". E o atraso era realmente clamoroso, social e econômico do Brasil. A gente não pode exagerar nas tintas em relação ao atraso. $\mathrm{O}$ atraso era assustador.

- No entanto, ele foi capaz de ver isso. Porque ele estava vendo o momento de ruptura com esse atraso. Começa lá nos anos 1930, sobretudo, em 1937. Vocês me perdoem, mas tem que observar, com o Estado Novo, com as políticas [...] Se vocês lerem - eu tive a oportunidade de ganhar de um amigo, funcionário do Banco do Brasil (apontando para uma pessoa presente); ele está rindo aqui porque acabou na mão dele - os relatórios do Banco do Brasil de 1930 a 1939. É uma coisa de uma lucidez, de uma clareza, de uma intencionalidade, do ponto de vista da ruptura com os fazendões atrasados. E a tentativa de encaminhar o país na cena da industrialização, que, na verdade, serve ... O que Celso pensa, tanto na Formação Econômica do Brasil - cujo prefácio eu fiz; não sei se vocês receberam, foi distribuído para vocês; receberam, né? Não vou repetir aqui aquilo que escrevi no prefácio - mas, a Formação Econômica do Brasil já é uma visão que está marcada por essa perspectiva. Vai da colônia ao início do século XIX. Do capitalismo à coisa do assalariamento, do assalariamento ao fim da escravidão, aí passa para os anos 1920 e 1930, aí vai em frente. É uma construção em que se espraia essa dinâmica histórica. Eu acho que isso é importantíssimo porque, nós, aqui na Unicamp, começamos a desenvolver o debate sobre o Brasil a partir dessa perspectiva da Cepal, com Celso Furtado. Ele foi importantíssimo, assim como foram outros. Mas, o fato é que o que ele está dizendo - por isso é que se chama Formação Econômica do Brasil - é 
[que é] impossível se entender uma formação econômica e social sem [se] ter uma ideia sobre a gênesis de desenvolvimento e desfecho. Se vocês olharem depois os outros livros que ele escreveu, como Teoria do Subdesenvolvimento, Desenvolvimento e Subdesenvolvimento, Análise do Modelo Brasileiro, vocês vão ver que ele está permanentemente na busca de prosseguir nessa empreitada. Tem uma linha de continuidade. Tem alguns livros que são melhores, outros que são piores. Isso é normal. Por exemplo, eu acho que $A$ Dialética do Desenvolvimento tem problema. Isso é outra coisa. Eu dizia para ele. Não é porque eu dizia, porque eu me dava muito bem com ele. E ele gostava muito da gente. Mas eu tenho divergências, né?

- Agora, ele, na verdade, construiu um paradigma de análise histórica e de dinâmica da economia capitalista, o que é considerado uma inovação. Infelizmente, eu vejo hoje as discussões sobre globalização. No outro livro que ele escreveu mais recentemente, há um capítulo sobre globalização. O que é, na verdade, muito interessante, porque ele desdobra a partir da primeira globalização, que era o final do século XIX. Parece que houve uma globalização ali, né? Muito peculiar. E essa globalização, na verdade, deu origem na redefinição estrutural da economia global. Não sei se vocês estudam isso aqui. Mas, o final do século XIX foi o sinal da emergência da Alemanha e dos Estados Unidos, como rivais, muitos parecidos, mas como rivais que destronaram a Inglaterra. Mas, que nascem - e isso é que é interessante - das relações entre uma economia pioneira industrialmente e as economias retardatárias da Europa. Mas, o estilo de articulação proposto pela economia dominante favoreceu a industrialização dos rivais. É o que ele vai mostrando durante toda a obra dele: essas interrupções e essas mudanças que o macroeconomista é incapaz de acompanhar, não vai perceber.

- Quando ele analisa, por exemplo, a questão dos termos de intercâmbio. O que são os termos de intercâmbio? É o fenômeno da diferença entre a produtividade dos países centrais e a dependência na periferia do papel da demanda externa na formação da renda. Aliás, a Formação Econômica do Brasil está prenhe disso. Celso tem uma abordagem muito interessante entre essa mudança estrutural, o fim da escravidão e o assalariamento, porque aí o processo de formação da renda muda. 
- Eu me lembro aqui de um debate que nós tivemos na Unicamp. Uma corrente achava que a escravidão era compatível com o desenvolvimento industrial (falando com uma pessoa presente). Não sei se vocês se lembram disso? Lembram? Não vou falar o nome aqui. Na verdade, ao contrário de Celso, esse professor não entendeu bem o que era a Revolução Industrial como mudança das relações sociais. E que mudança da relação social? É o assalariamento. Você tem que pagar uma renda monetária para o trabalhador. E o trabalhador se transforma num demandante dos seus produtos. Uma coisa elementar, porque a Revolução Industrial muda completamente a dinâmica das economias. E muda também aqui. A despeito de exportadores de produtos primários. Devemos ao Wilson Cano, a quem eu presto minha homenagem aqui, a ideia do complexo do cafeeiro.

- Eu estava conversando com ele... Há, às vezes, uma subestimação do papel do complexo cafeeiro na criação de condições - e Celso analisa bem - para a emergência da indústria. Porque o complexo cafeeiro tinha capacidade de gerar uma certa divisão do trabalho. $\mathrm{O}$ sistema financeiro, por exemplo, incumbido de financiar o café, o sistema comercial, a construção das ferrovias, né?

- É que vocês são muito jovens. Vocês não têm muita clareza - eu imagino, e não são obrigados a ter - sobre o papel dos cafeicultores paulistas, com todas as restrições que a gente possa ter [em relação] a eles, na condição do sistema de transporte de São Paulo, que era um sistema ferroviário, infelizmente, destruído, posteriormente, mas que era muito importante. E isso deu os primeiríssimos passos, os primeiríssimos, no setor incipiente de bens de capital. Por exemplo, o senhor Bardella tinha uma empresa, o pai dele, um italiano, [que] veio para cá e fez uma empresa que fazia equipamentos para reparos nas ferrovias.

- Quem conheceu bem, e eu via bem isso viajando para o interior de trem, você tinha enormes centrais para reparações, que demandavam componentes, às vezes, peças da indústria incipiente brasileira. Então, a ferrovia teve uma importância grande na diversificação da economia cafeeira, assim como o comércio também teve. As chamadas [...] casas de comercialização do café, os bancos, as ferrovias... 
- Nesse complexo cafeeiro, você tem o surgimento de uma indústria leve. Ou seja, o Matarazzo produzia banhas, depois passou a produzir tecidos, velas, sabão, que a professora Liana Aureliano chamou, em sua tese de doutoramento, de industrialização restringida, a indústria que estava ligada à expansão do sistema cafeeiro. O Celso Furtado percebe muito bem como isso ocorre, e como se transforma mais tarde. Porque Furtado percebeu, como o professor João Manoel percebeu, que o crucial para botar uma industrialização capitalista é [...] montar seu setor de bens de capital. E isso foi feito. Quando é que a CSN foi negociada? 1944. Aí a industrialização brasileira deu um salto e Celso Furtado vai lá e registra isso corretamente. Aí é uma mudança fundamental. Em cima disso, a industrialização pôde prosseguir. E Juscelino pôde fazer o que fez. O Brasil teve a maior concentração de empresas produtora de equipamentos pesados para energia elétrica por exemplo - no mundo! Mais do que os Estados Unidos. Hoje não tem mais. Isso é só para ilustrar a conversa.

- O que eu quero mostrar para vocês é que é imprescindível, na observação do desenvolvimento da economia brasileira, ter claro que você está lidando com a dinâmica das estruturas. E as dinâmicas das estruturas nunca são lineares. Vou usar uma palavra aqui - vocês me perdoem usar - que costuma ser contraditória. Celso Furtado tinha muito claro que precisava usar a imaginação. Certa vez ele se confessou positivista. Eu escrevi, aqui, uma orelha do livro dele, em que ele diz: "Eu sou positivista, não a caricatura que circula hoje em dia, mas a ideia de que o Homem tem meios para transformar o mundo. Construir um mundo melhor, que esses meios estão ordenados pela Ciência, decorrem do avanço formidável do conhecimento científico". Olha só como ele era um positivista autêntico, legítimo. "Quando descobri a ideia de planejamento social fiquei maravilhado, e disse: Aqui está o caminho. Temos que sair por aqui". Vocês sabiam disso? "Para aplicar a inteligência, para ordenar a cidade, tem que ter um plano, e então me pus a estudar o planejamento".

- Olha só o que ele fala. Se Furtado se entregasse apenas às dinâmicas das estruturas, podia argumentar: "Não há o que fazer. Temos que esperar que essa totalidade se desenvolva". Não! Ele olhava isso como uma oportunidade para a ação humana. Ele não era positivista. Ele 
achava que era, mas não era. Ele era muito mais um marxista, sem saber. O marxismo ainda do tempo dele [...] Era assim, digamos, marxismo positivista, né? Ele achava que você tinha determinismos. Vocês desculpem eu falar isso, a coisa mais injusta, mais iníqua com Marx é dizer que ele era determinista. A história dele está cheia de incertezas, cheia de momentos em que a ação humana é que tem que resolver. Então, é isso o que pensa Celso Furtado, no conjunto de sua obra. Por exemplo, naquele livro que ele publicou, O Brasil Pós-“milagre”, que é um livro muito interessante. E o melhor deles, que é Criatividade e Dependência na Civilização Industrial. Esse livro é muito interessante. O Brasil Pós-"milagre” também merece uma leitura cuidadosa.

- E o livro dele sobre a cultura? Porque Celso foi Ministro da Cultura do governo [José] Sarney. Vocês sabiam disso? Sabiam. No governo, ele convivia muito conosco e começou a dar uma importância cada vez maior à cultura. A cultura não no sentido elitista, né? A cultura no sentido da disseminação, do debate entre as pessoas, para que compreendessem o ambiente histórico em que viviam [...] Furtado passou a perceber que o desenvolvimento em si mesmo não conduzia, necessariamente, a uma mudança cultural. Não, necessariamente.

- Aliás, eu preciso dizer para vocês [...] Eu não gostaria de falar, mas vou ter que falar [...] Nós hoje estamos observando o fenômeno da regressão cultural. Não estou dizendo que é um fenômeno que atinge todos os brasileiros, mas uma boa parte deles. E esses fenômenos acontecem. E ele tinha muito claro que era importante ter projetos culturais muito envolventes para a população como um todo. Ele via isso como uma dimensão da democratização.

- Então, dizia o [Theodor] Adorno: "Não há liberdade sem compreensão". Vocês sabem quem é Adorno. Na Dialética do Esclarecimento ele dizia: "Não há liberdade sem compreensão". Ou seja, a compreensão é aquela que o Homem desenvolve para se mover no seu espaço de sociabilidade, no seu espaço social. Você precisa ter compreensão, perceber onde está enfiado. Ele [Celso Furtado] se preocupava muito com isso. Eu lembro que tivemos uma conversa na casa do doutor Ulysses Guimarães, a quem Luciano Coutinho, João Manuel e eu servimos, modestamente, nos anos 1970 e 1980, até ele morrer. Celso fez uma digressão sobre a importância da cultura. A importância não da 
cultura - vou repetir - no sentido elitista, dos cultos versus incultos. Não era isso. Era a cultura como você entregar ao outro uma capacidade de se questionar, de reconhecer, o que é fundamental para a sociedade, reconhecer o outro como interlocutor válido. Ele falou: "Olha, eu estou preocupado com o Plano Cruzado".

Gudin tinha razão: Furtado seria um bom romancista, já que escrevia bem. Mas, ele respondeu que não iria abandonar o uso da imaginação para pensar a situação dos países periféricos.

Furtado não era de dar lições. Era de conversar. "Eu estou preocupado porque vejo que, na verdade, houve uma mobilização excessiva, meio apaixonada".

- Gudin tinha razão, Furtado seria um bom romancista, já que escrevia bem. Mas, ele respondeu que não iria abandonar o uso da imaginação para pensar a situação dos países periféricos.

- Eu vou encerrar aqui. 